\title{
Analysis of longitudinal oncology quality of life (QoL) data - are we getting it right?
}

\author{
Kim Cocks ${ }^{*}$, Puvan Tharmanathan ${ }^{1}$, Adam Smith² \\ From 2nd Clinical Trials Methodology Conference: Methodology Matters \\ Edinburgh, UK. 18-19 November 2013
}

\section{Background}

Quality of Life (QoL) data from oncology trials may have missing data which cannot be assumed to be missing completely at random (MCAR) [1]. Ignoring this missing data in analysis may introduce bias. A number of statistical techniques to deal with informative missing data are available [2], but may be underutilised.

\section{Methods}

We searched MEDLINE (2002-2012) to identify oncology trials reporting longitudinal analysis of QOL data. The appropriateness of the analysis was reviewed and trials reporting QOL as primary/secondary endpoint were assessed for reporting quality using the CONSORT extension for PROs [3].

\section{Results}

69 RCTs reporting longitudinal QOL analyses were identified. 29 (42\%) use an analysis to account for the nature of the missing data. Methods varied widely, eg pattern-mixture models, conditional linear models, QTWiST, joint longitudinal models, generalised estimating equations, selection models and Markov models. Fourteen papers used more than one method check the robustness of their results.

\section{Conclusions}

In order for QOL data to adequately inform clinical decision-making the correct analysis needs to be performed. Statistical methods ignoring the missing data were found to over-estimate QOL but it was rare for the significance of QOL differences between treatments to change. A strategy for appropriate analysis of QOL data will be presented using case studies to highlight

${ }^{1}$ York Clinical Trials Unit, Department of Health Sciences, University of York, York, UK

Full list of author information is available at the end of the article where ignoring informative missing data could alter the conclusions regarding treatment differences.

\section{Authors' details \\ ${ }^{1}$ York Clinical Trials Unit, Department of Health Sciences, University of York, York, UK. ${ }^{2}$ York Health Economics Consortium (YHEC) and Research Innovation Office, University of York, York, UK. \\ Published: 29 November 2013 \\ References \\ 1. Bell ML, Fairclough DL: Practical and statistical issues in missing data for longitudinal patient reported outcomes. Stat Methods Med Res 2013. \\ 2. Fairclough DL: Design and Analysis of Quality of Life Studies in Clinical Trials. CRC Press: London; 2010. \\ 3. Calvert M, Blazeby J, Altman DG, Revicki DA, Moher D, Brundage MD, CONSORT PRO Group: Reporting of patient-reported outcomes in randomized trials: the CONSORT PRO extension. JAMA 2013, 309(8):814-22.}

doi:10.1186/1745-6215-14-S1-P105

Cite this article as: Cocks et al:: Analysis of longitudinal oncology quality of life (QoL) data - are we getting it right? Trials 2013 14(Suppl 1):P105.

Submit your next manuscript to BioMed Central and take full advantage of:

- Convenient online submission

- Thorough peer review

- No space constraints or color figure charges

- Immediate publication on acceptance

- Inclusion in PubMed, CAS, Scopus and Google Scholar

- Research which is freely available for redistribution
C Biomed Central

C 2013 Cocks et al; licensee BioMed Central Ltd. This is an Open Access article distributed under the terms of the Creative Commons Attribution License (http://creativecommons.org/licenses/by/2.0), which permits unrestricted use, distribution, and reproduction in any medium, provided the original work is properly cited. 